Check for updates

Cite this: Chem. Sci., 2019, 10, 475

๑ All publication charges for this article have been paid for by the Royal Society of Chemistry

Received 5th July 2018

Accepted 15th October 2018

DOI: $10.1039 / c 8 s c 02979 b$

rsc.li/chemical-science

\section{Selective deoxygenation of nitrate to nitrosyl using trivalent chromium and the Mashima reagent: reductive silylation $\uparrow$}

\author{
Junghee Seo, (D) Alyssa C. Cabelof, (D) Chun-Hsing Chen (D) \\ and Kenneth G. Caulton (D)*
}

1,4-Bis(trimethylsilyl)-1,4-diaza-2,5-cyclohexadiene is an effective silyl transfer reagent towards the oxygen of nitrate coordinated to $\mathrm{Cr}(\mathrm{III})$ in a pincer complex. Two nitrate oxygens are removed to give the 17 valence electron octahedral complex $\left(\mathrm{H}_{2} \mathrm{~L}\right) \mathrm{Cr}\left(\mathrm{NO}_{3}\right)_{2}(\mathrm{NO})$. This is shown by a variety of spectroscopic methods, together with DFT, to be a $\mathrm{Cr}(\mathrm{I})$ complex with a linear $\mathrm{CrNO}$ unit. This work also identifies future applications of this reductive silylation process.

\section{Introduction}

This is the age of anthropogenic perturbation of the natural nitrogen cycle. ${ }^{\mathbf{1}, 2}$ Nitrogen is a limiting factor for agricultural production of food. Nitrogenous fertilizers, ammonia and ammonium nitrate, produced by the Haber-Bosch process, are crucial to meet that increasing food demand. An unintended consequence of meeting planetary food needs is increased runoff of $\mathrm{NO}_{3}{ }^{-}$, produced by soil bacteria, into ground water, which results in excessive growth of plants and algae (eutrophication) in poorly drained bodies of water. This problem demands new approaches to deoxygenation of nitrate. In contrast to deoxygenation of $\mathrm{N}^{\mathrm{V}}$, abstraction of $\mathrm{O}$ atoms from a metal oxo complex can be accomplished by a low valent metal

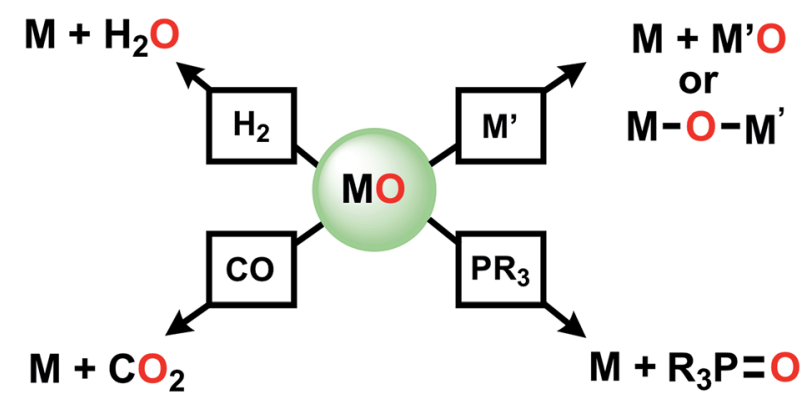

Scheme 1 Precedent of oxygen atom transfer reactions.

Indiana University, Department of Chemistry, 800 E. Kirkwood Ave., Bloomington, IN, 47401, USA. E-mail: caulton@indiana.edu

$\dagger$ Electronic supplementary information (ESI) available: NMR, MS (ESI, APCI), FT-IR, EPR, XPS, CV, DFT, and crystal structure data for $\mathrm{H}_{2} \mathrm{LCr}\left(\mathrm{NO}_{3}\right)_{2}(\mathrm{NO})$. CCDC 1848665. For ESI and crystallographic data in CIF or other electronic format see DOI: $10.1039 / \mathrm{c} 8 \mathrm{sc} 02979 \mathrm{~b}$
$\mathbf{M}^{\prime}$ (Scheme 1) via "oxygen atom transfer", but this reaction can often merely form a bridging $\mathrm{MOM}^{\prime}$ complex. $^{3-6} \mathrm{O}$ atom abstraction can sometimes occur by two electron reduction by $\mathrm{PR}_{3}$, by CO, rarely and under forcing conditions with $\mathrm{H}_{2}$, or in more complicated transformations with boron hydrides. ${ }^{7}$

On the other hand, our efforts to deoxygenate nitrate focus on the use of unconventional reagents. Kaim reported the electron rich character of silylated nitrogen heterocycles, generally $8 \pi$ electron molecules. ${ }^{8,9}$ These bis-silylated nonaromatic reagents were shown by Mashima and Tsurugi to reduce metal in $\mathrm{MCl}_{n}$ by abstracting chlorine, based on favorable thermodynamics of forming the $\mathrm{Si}-\mathrm{Cl}$ bond and the energetic benefit of aromatization of the ring. ${ }^{10}$ We focus here on 1,4bis(trimethylsilyl)-1,4-diaza-2,5-cyclohexadiene (Mashima reagent, $\mathbf{1}$, Scheme 2 ). In reagent $\mathbf{1}$, the $\mathrm{Si}-\mathrm{N}$ bond dissociation energy should be weak, just as the doubly allylic $\mathrm{C}-\mathrm{H}$ bonds in 1,4-cyclohexadiene are. Both nonmetal products, pyrazine and $\mathrm{Me}_{3} \mathrm{SiCl}$, are volatile and thus readily removed and so this is termed by the discoverers as a "salt-free reduction route;" this is

a)

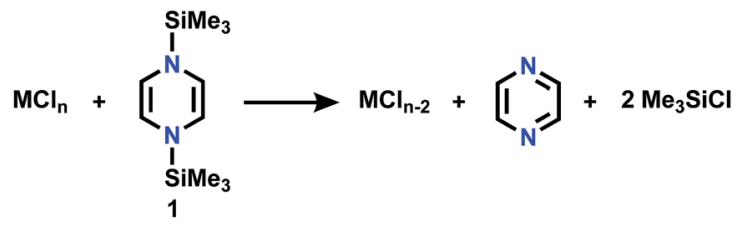

b)

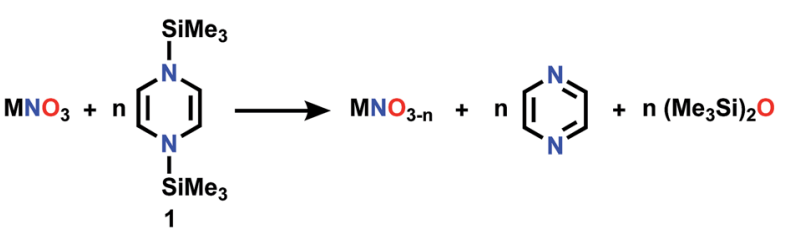

Scheme 2 (a) Reductive silylation reaction using Mashima reagent (b) deoxygenation reaction using Mashima reagent. 
in contrast to elemental metal reductants, where the resulting oxidized metal halide can be challenging to remove. Subsequent reports have shown other applications including reduction of $4 \mathrm{~d}$ and highly electropositive metals (niobium), ${ }^{\mathbf{1 1}}$ dechlorination of geminal dihalides to olefins, ${ }^{\mathbf{1 2}}$ and double silylation of metal oxides $\mathrm{MO}_{n}$ to yield reduced metal oxide. ${ }^{\mathbf{1 3 , 1 4}}$ The method has also been applied in main group reductions ${ }^{\mathbf{1 5}}$ and nanoparticle synthesis. ${ }^{\mathbf{1 6}}$

Dechlorination $\left(\mathrm{MCl}_{n} \rightarrow \mathrm{MCl}_{n-1}\right)$ (Scheme 2a) is a single electron reduction, but the Mashima reagent has special appeal for deoxygenation (Scheme 2b), since it appears to have the ability to accomplish a 2 -electron reduction in a single molecular collision, a rare capacity among reductants. We report here new applications of reductive silylation: deoxygenation of coordinated $\mathrm{NO}_{x}{ }^{-}$of relevance to remediation of nitrate-based eutrophication. ${ }^{17-22}$

\section{Results and discussion}

For comparison, there is no reaction between $\left[\mathrm{Ph}_{3} \mathrm{PNPPh}_{3}\right] \mathrm{NO}_{3}$ and 1 in $\mathrm{CD}_{2} \mathrm{Cl}_{2}$ even after $72 \mathrm{~h}$ at $50{ }^{\circ} \mathrm{C}$. A nitrate complex containing bis(pyrazol-3-yl)pyridine $\left(\mathrm{H}_{2} \mathrm{~L}\right)$ ligand (Scheme 3), was chosen to be proton responsive, redox active, and carry useful ${ }^{1} \mathrm{H}$ NMR spectroscopic reporter substituents for paramagnetic species. Reaction of $\left(\mathrm{H}_{2} \mathrm{~L}\right) \mathrm{Cr}\left(\mathrm{NO}_{3}\right)_{3}$ with 1 in $\mathrm{CH}_{2} \mathrm{Cl}_{2}$ at a $1: 3$ mole ratio is complete within 5 minutes, and the product shows a ${ }^{1} \mathrm{H}$ NMR spectrum consistent with equivalent pyrazole arms, showing a paramagnetically shifted ${ }^{t} \mathrm{Bu}$ resonance along with the stoichiometric amount of byproducts, hexamethyldisiloxane and pyrazine (see ESI $\dagger$ ). The IR spectrum shows a strong absorption at $1720 \mathrm{~cm}^{-1}$, possibly indicative of a nitrosyl. Absorptions are also seen at 1484, 1415, 1313, 1285, and $990 \mathrm{~cm}^{-1}$ which are attributed to NO stretching and bending motions, but are not uniquely diagnostic of $\mathrm{NO}_{x}$ formula. The $\operatorname{ESI}(-)$ and $\operatorname{APCI}(-)$ mass spectra both show an ion of formula $\operatorname{LCr}\left(\mathrm{N}_{2} \mathrm{O}_{4}\right)^{-}$, while both positive ion methods show $\left(\mathrm{H}_{2} \mathrm{~L}\right) \mathrm{Cr}\left(\mathrm{N}_{2} \mathrm{O}_{4}\right)^{+}$. Single crystal X-ray diffraction of crystals grown by vapor diffusion of cyclohexane into a saturated THF solution were found to have formula $\left(\mathrm{H}_{2} \mathrm{~L}\right) \mathrm{Cr}\left(\mathrm{NO}_{3}\right)_{2}(\mathrm{NO})$, with NO trans to the pyridine $\mathrm{N}$. This is therefore designated a $\{\mathrm{CrNO}\}^{5}$ configuration, ${ }^{23,24}$ which are relatively common $\mathrm{S}=1$ / 2 species (e.g. $\mathrm{Cr}(\mathrm{NO}) \mathrm{L}_{5}{ }^{2+}$ where $\mathrm{L}=\mathrm{NH}_{3}, \mathrm{H}_{2} \mathrm{O}$ or DMSO). ${ }^{25-34}$ Another analog is (picolinate) $\mathrm{Cr}(\mathrm{NO})\left(\mathrm{H}_{2} \mathrm{O}\right)_{2}$, synthesized in a completely different way, from $\mathrm{Cr}^{\mathrm{VI}}$ and reductant $\mathrm{NH}_{2} \mathrm{OH} \cdot{ }^{35,36}$
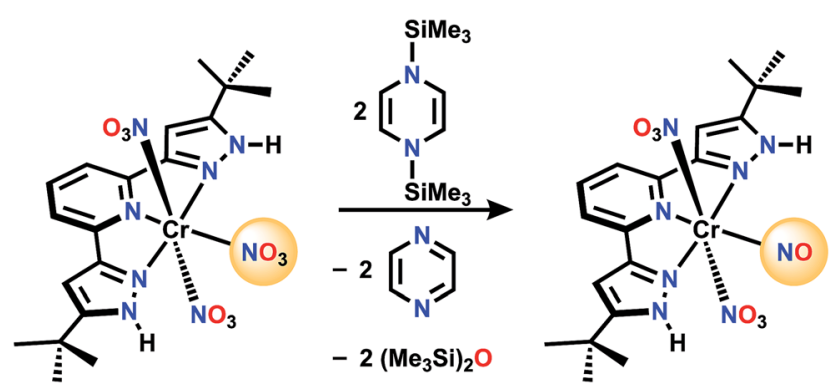

Scheme 3 Reaction of $\left(\mathrm{H}_{2} \mathrm{~L}\right) \mathrm{Cr}\left(\mathrm{NO}_{3}\right)_{3}$ with the Mashima reagent.
In those cases the $\mathrm{Cr} / \mathrm{L}$ distance trans to the nitrosyl is always longer than those $\mathrm{Cr} / \mathrm{L}$ cis to NO, consistent with a strong trans influence of the nitrosyl. In all cases, the $\mathrm{CrNO}^{2+}$ unit is linear, consistent with $\mathrm{NO}^{+}$assignment, hence the product here is low spin $\mathrm{Cr}(\mathrm{I})$. This is consistent with 5 electrons in the $\mathrm{t}_{2 \mathrm{~g}}$ derived orbitals, which maximizes back donation to $\mathrm{NO}^{+}$in contrast to what would be true if any electrons populated the $\mathrm{e}_{\mathrm{g}}$-derived orbital in a high spin alternative. The species $\operatorname{LCr}\left(\mathrm{N}_{2} \mathrm{O}_{4}\right)^{-}$ observed by mass spectrometry is therefore the result of loss of two protons and one weakly bound nitrate in the ionization process, to form species $\mathrm{LCr}\left(\mathrm{NO}_{3}\right)(\mathrm{NO})^{-}$.

Single crystal X-ray diffraction (Fig. 1) shows an octahedral structure with nitrosyl trans to pyridine nitrogen. NH protons do not hydrogen bond intramolecularly to nitrate oxygen, but instead to two THF molecules $(\mathrm{O} / \mathrm{N}=2.77 \AA)$ which cocrystallize (see $\mathrm{ESI} \dagger$ ). The nitrate ligands rotate in opposite directions (yielding idealized molecular $\mathrm{C}_{2}$ symmetry), achieving $\mathrm{O} / \mathrm{N} \beta(\mathrm{pz})$ distances of $3.06 \AA$. In fact those oxygens have approaches in the narrow range of 2.898-3.100 to both pyrazole nitrogens and the nitrosyl nitrogen. The $\mathrm{Cr} / \mathrm{NO}$ distance is short $(1.724(6) \AA)$, as is the NO distance $(1.160(9)$ $\AA)$. The nitrate ONO angles lie within the range 116.6-124.0 and the $\mathrm{CrON}$ angles are both $126.5^{\circ}$, consistent with $\mathrm{sp}^{2}$ hybridization. Binding nitrate to $\mathrm{Cr}$ here lengthens the $\mathrm{N}-\mathrm{OCr}$ distance to $1.296 \AA$ from the other four nitrate NO values of 1.219-1.251 $\AA$; these are all longer than the triple bond in the nitrosyl. The exceptional result here is that four electron reduction of $\left(\mathrm{H}_{2} \mathrm{~L}\right) \mathrm{Cr}\left(\mathrm{NO}_{3}\right)_{3}$ occurs entirely on one nitrate ligand, not distributed over two. While this might first appear to mean production of $\mathrm{NO}^{-}\left(\mathrm{NO}_{3}^{-} \rightarrow \mathrm{NO}^{-}+2\right.$ "O"), this undergoes intramolecular two electron reorganization with

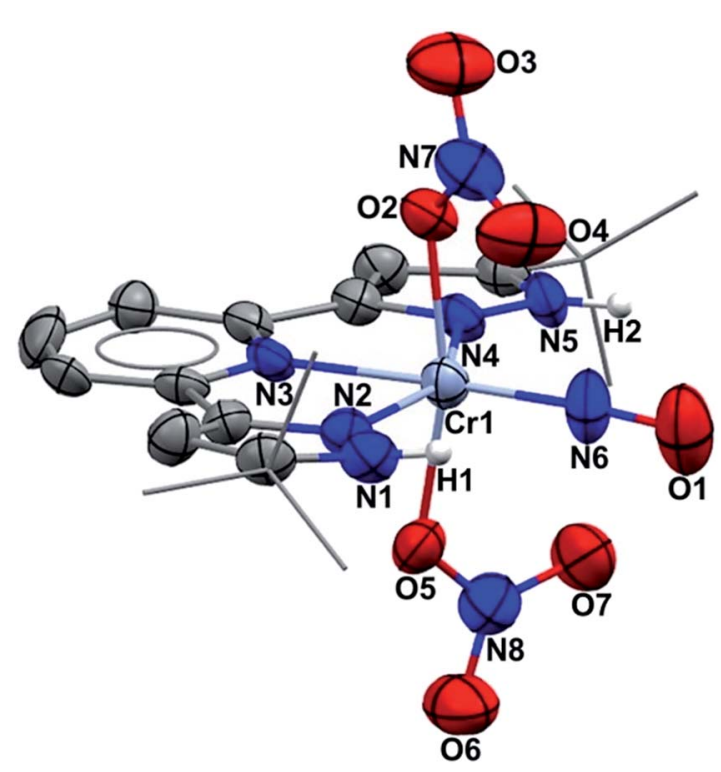

Fig. 1 Mercury drawing (50\% probabilities) of $\left(\mathrm{H}_{2} \mathrm{~L}\right) \mathrm{Cr}\left(\mathrm{NO}_{3}\right)_{2}(\mathrm{NO})$, showing selected atom labelling. Unlabeled atoms are carbon and THF molecules hydrogen bonding to both $\mathrm{NH}$ protons are omitted, for clarity. Selected structural parameters (Å): $\mathrm{Cr} 1-\mathrm{O} 2,2.017(6)$; $\mathrm{Cr} 1-\mathrm{O} 5$, 2.003(6); Cr1-N2, 2.075(7); Cr1-N3, 2.078(5); Cr1-N4, 2.074(6); Cr1$\mathrm{N} 6,1.724(6) ; \mathrm{O} 1-\mathrm{N} 6,1.160(9)$. 
initially $\mathrm{Cr}(\mathrm{III})$ to yield the observed $\left[\mathrm{Cr}^{\mathrm{I}}\left(\mathrm{NO}^{+}\right)\right]^{2+}$ product. $\mathrm{Cr}^{\mathrm{I}}$ is an unusual oxidation state, and $\left(\mathrm{H}_{2} \mathrm{~L}\right) \mathrm{Cr}\left(\mathrm{NO}_{3}\right)_{2}(\mathrm{NO})$ is a 17 valence electron species, but this deficit from 18 electron count follows due to the absence of any single electron reductant in the synthesis.

The XPS spectrum of $\left(\mathrm{H}_{2} \mathrm{~L}\right) \mathrm{Cr}\left(\mathrm{NO}_{3}\right)_{2}(\mathrm{NO})$ was obtained to evaluate the resolution of this technique as well as its utility for obtaining atom ratios, including oxygen. Four samples were assayed to establish reproducibility. The measured $\mathrm{Cr} 2 \mathrm{p}_{3 / 2}$ binding energy was $577.0 \mathrm{eV}$, consistent with an oxidation state below $3^{+} \cdot{ }^{37}$ The $\mathrm{N} 1 \mathrm{~s}$ region resolved three types of nitrogen, with populations $2: 1: 5$, consistent with nitrate (406.6 eV), nitrosyl $(402.1 \mathrm{eV})$ and pincer ligand $(400.2 \mathrm{eV})$. There was no resolution of the three types of oxygen, but the atom ratios of $\mathrm{Cr}: \mathrm{N}: \mathrm{O}$ were within $10 \%$ of the theoretical values $1: 8: 7$.

The EPR spectrum of $\left(\mathrm{H}_{2} \mathrm{~L}\right) \mathrm{Cr}\left(\mathrm{NO}_{3}\right)_{2}(\mathrm{NO})$ shows a typical pattern ${ }^{38-40}$ for an $\mathrm{S}=1 / 2$ species, including satellites for $\mathrm{A}\left({ }^{53} \mathrm{Cr}\right)$ $=13.4 \times 10^{-4} \mathrm{~cm}^{-1}$. In a THF solution at $25{ }^{\circ} \mathrm{C}$, there is no resolved coupling to any ligand ${ }^{14} \mathrm{~N}$, consistent with $\mathrm{A}\left({ }^{14} \mathrm{~N}\right)<7 \times$ $10^{-4} \mathrm{~cm}^{-1}$, as well as consistent with the negligible nitrogen character in the calculated SOMO (Fig. 2b).

DFT calculations (BP86/6-311G(d)) on $\left(\mathrm{H}_{2} \mathrm{~L}\right) \mathrm{Cr}\left(\mathrm{NO}_{3}\right)_{2}(\mathrm{NO})$ were used to establish the distribution of electrons within the $\{\mathrm{CrNO}\}^{5}$ unit. The calculated NO stretching frequency is $1746 \mathrm{~cm}^{-1}$, in satisfactory agreement with the experimental value of $1720 \mathrm{~cm}^{-1}$; both experimentally and computationally, this vibration is the most intense of all modes. The calculated nitrosyl complex has structural parameters in full agreement with the crystallographic ones. Mulliken spin densities are

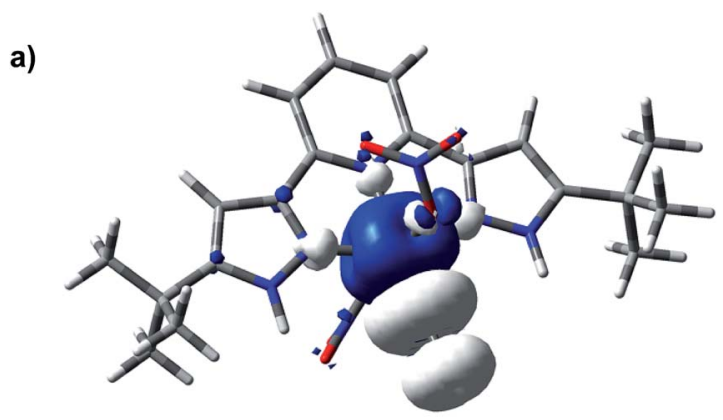

b)
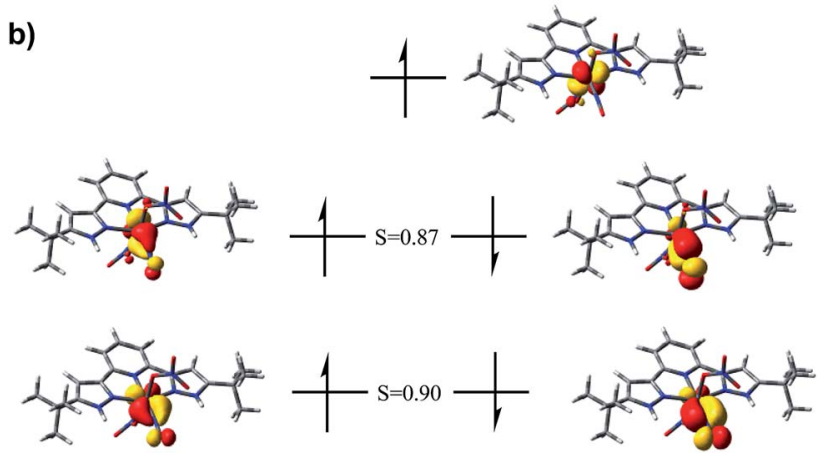

Fig. 2 (a) Spin density plot for $\left(\mathrm{H}_{2} \mathrm{~L}\right) \mathrm{Cr}\left(\mathrm{NO}_{3}\right)_{2}(\mathrm{NO})$ plotted on an isosurface value of $0.002 \mathrm{au}$. (b) Corresponding orbital analysis for $\left(\mathrm{H}_{2} \mathrm{~L}\right)$ $\mathrm{Cr}\left(\mathrm{NO}_{3}\right)_{2}(\mathrm{NO})$ plotted on an isosurface value of $0.05 \mathrm{au}$. +2.2e on $\mathrm{Cr},-0.69 \mathrm{e}$ on nitrosyl $\mathrm{N}$ and $-0.50 \mathrm{e}$ on nitrosyl $\mathrm{O}$, then negligible elsewhere. [see ESI $\dagger$ ]. These are likewise consistent with the spin density plot in Fig. 2a.

Corresponding orbitals ${ }^{41}$ from an unrestricted calculation (Fig. 2b) show five electrons located in primarily $\mathrm{t}_{2 \mathrm{~g}}$-derived $\mathrm{Cr}$ $\mathrm{d}$ orbitals, with high $\alpha / \beta$ overlap values. This is consistent with four paired electrons in orbitals of $\pi$ symmetry with respect to the CrNO line, each of these have some $\pi_{\mathrm{NO}}^{*}$ character, indicative of back donation from metal to $\mathrm{NO}^{+}$. This also shows a SOMO which is on $\mathrm{Cr}$, and of delta symmetry with respect to the NO, hence having no NO character. There is no spin density on $\mathrm{H}_{2} \mathrm{~L}$ or on nitrate. Overall, this is consistent with the $\mathrm{d}^{5}$ configuration of $\mathrm{Cr}^{\mathrm{I}}$ with significant back-donation into the nitrosyl $\pi^{*}$. These results are consistent with EPR parameters and DFT results for analogous $\mathrm{CrL}_{5}(\mathrm{NO})$ species. ${ }^{25-39}$

Mechanistically, beyond the more obvious double deoxygenation $^{42}$ of the same nitrate, other mechanisms can be considered. Scheme 4 envisions the alternative single deoxygenation of two nitrates, followed by two rearrangement steps of a bis-nitrito species which could then arrive at the observed product. We have used DFT to calculate the energies of various isomeric double deoxygenation products, to see which might be exergonic from a given isomer, vs. potentially highly endergonic. Species $\mathbf{A}$ and $\mathbf{C}$ are $\mathbf{S}=3 / 2$ and $\mathbf{B}$ and $\mathbf{D}$ are $S=1 / 2$. Of special note in Scheme 4 is the CrON "isonitrosyl" species $\mathbf{B}^{\mathbf{4 3}}$ which is found at extremely high energy, and thus not mechanistically relevant. For additional discussion of the electronic structure of this species, see ESI. $\dagger$ DFT calculations show that $\mathrm{S}$ $=3 / 2$ states of the two species $\mathbf{A}$ and $\mathbf{C}$ are nearly isoenergetic (nitro isomer is $3.8 \mathrm{kcal} \mathrm{mol}^{-1}$ more stable), so interconversion of these is expected to be facile.

In order to quantitate the degree to which trading $\mathrm{NO}$ for $\mathrm{SiO}$ bonds yields favorable thermodynamics, we calculated the energy for the double deoxygenation reaction of $\mathrm{H}_{2} \mathrm{LCr}\left(\mathrm{NO}_{3}\right)_{3}$ to $\mathrm{H}_{2} \mathrm{LCr}\left(\mathrm{NO}_{2}\right)_{2}\left(\mathrm{NO}_{3}\right)$ with two equivalents of the Mashima reagent [see ESI $\dagger$ for more details], with both reactant and product complexes in the $S=3 / 2$ spin state. Calculations were done at the BP86/6-311G(d) level of theory, giving a reaction free energy of $-158.1 \mathrm{kcal} \mathrm{mol}^{-1}$. This is the single deoxygenation of two nitrate groups, so the average of these, $\sim-80 \mathrm{kcal} \mathrm{mol}^{-1}$, shows the impressive thermodynamic potential of the Mashima reagent for reductive silylation.

The 17 valence electron count of this species suggests it should be subject to reduction to yield an 18 electron $\{\mathrm{CrNO}\}^{6}$ complex. Indeed, a range of 18 valence electron $[\mathrm{CrNO}]^{1+}$ species have been isolated, and connected to the 17 electron class via cyclic voltammetry. ${ }^{31,32} \mathrm{CV}$ of $\left(\mathrm{H}_{2} \mathrm{~L}\right) \mathrm{Cr}\left(\mathrm{NO}_{3}\right)_{2}(\mathrm{NO})$ in THF with $\mathrm{TBAPF}_{6}$ as supporting electrolyte at $0.1 \mathrm{~V} \mathrm{~s}^{-1}$ in the range +0.7 to $-3.0 \mathrm{~V}$ (vs. $\mathrm{Fc} / \mathrm{Fc}+$ ) shows a first reduction wave with $E_{\mathrm{pc}}=-2.18 \mathrm{~V}$ followed by two more current maxima at -2.55 and $-2.90 \mathrm{~V}$; there is no oxidation wave in that range. At sweep rates up to $1 \mathrm{~V} \mathrm{~s}^{-1}$, even the least negative of these reduction waves fails to show reversibility. This shows that one electron reduction occurs, but follow-up processes cause chemical change on the $\mathrm{CV}$ timescale, leaving no chance for reoxidation of transient $\left(\mathrm{H}_{2} \mathrm{~L}\right) \mathrm{Cr}\left(\mathrm{NO}_{3}\right)_{2}(\mathrm{NO})^{-}$. Given the reducible protons, as well as the pentavalent nitrogen in this anion, 


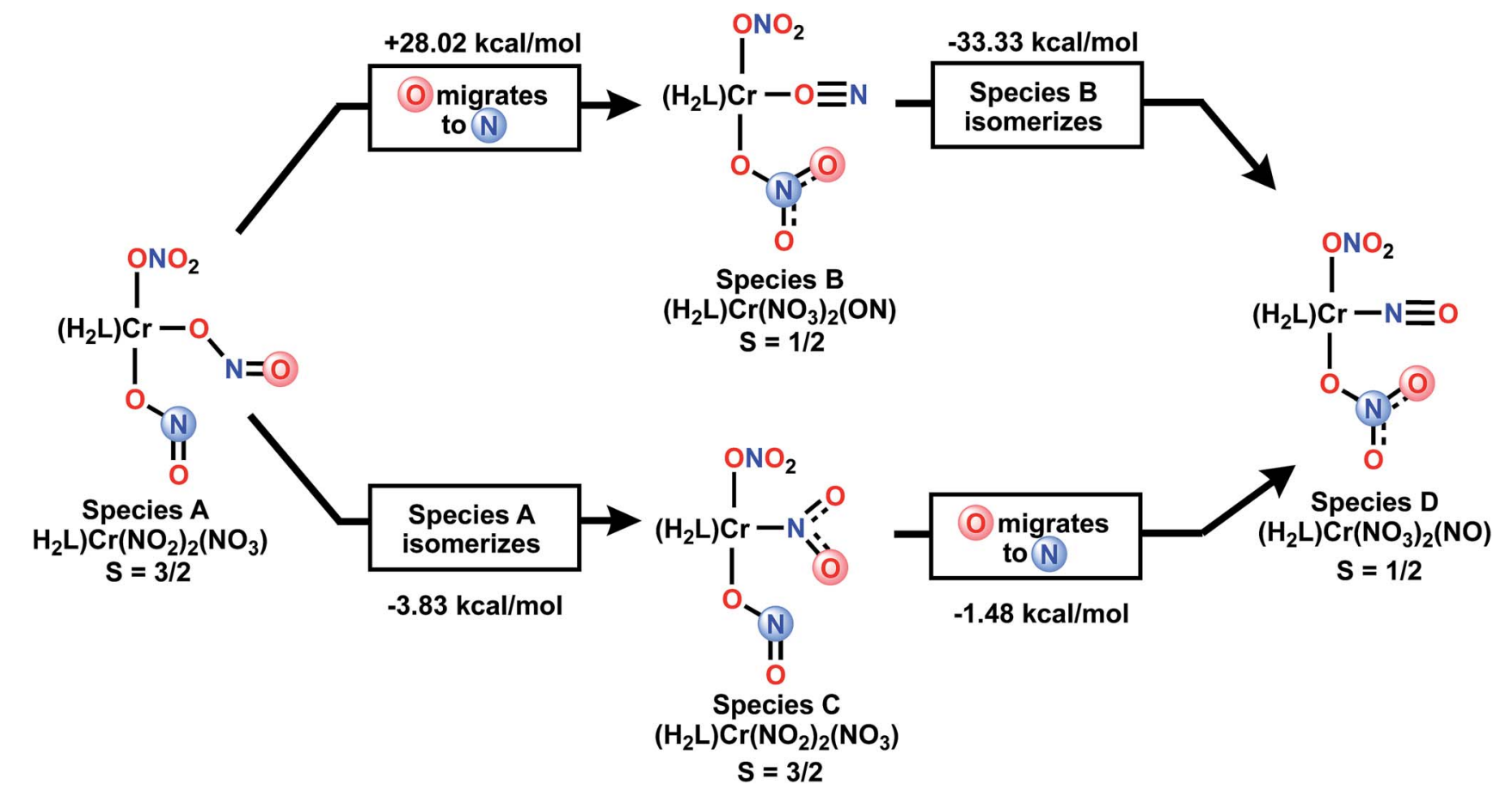

Scheme 4 DFT free energies of two isomerization mechanisms.

redox chemistry is a likely cause of the CV irreversibility. In any event, the neutral molecule is clearly established to have an orbital available for accepting an electron.

\section{Conclusions}

This work begins to show the potential of the Mashima reagent for deoxygenation of high valent nitrogen in coordinated nitrate under mild conditions. The activating effect of trivalent chromium is clearly important, as shown here by the lack of deoxygenation of free nitrate. Deoxygenation occurs twice to finally take nitrate to the coordinated nitrosyl oxidation level. The selective conversion of $\left(\mathrm{H}_{2} \mathrm{~L}\right) \mathrm{Cr}\left(\mathrm{NO}_{3}\right)_{3}$ to $\left(\mathrm{H}_{2} \mathrm{~L}\right) \mathrm{Cr}\left(\mathrm{NO}_{3}\right)_{2}(\mathrm{NO})$ shows that the weakly acidic $\mathrm{NH}$ protons are not reactive towards the silyl reagent; the reagent has oxophilic selectivity. The results reported here show that deoxygenation of nitrate is favored compared to conversion of $\left(\mathrm{H}_{2} \mathrm{~L}\right) \mathrm{Cr}^{\mathrm{III}}\left(\mathrm{NO}_{3}\right)_{3}$ with 1 to $\left(\mathrm{H}_{2} \mathrm{~L}\right) \mathrm{Cr}^{\mathrm{II}}\left(\mathrm{NO}_{3}\right)_{2}$, pyrazine and $\left(\mathrm{Me}_{3} \mathrm{Si}\right) \mathrm{NO}_{3}$. Further development of this reagent will benefit from better understanding of the mechanism of the reaction: electron transfer, silyl radical transfer, or concerted transfer of two silyl groups in a single molecular collision. ${ }^{4-46}$ Further topics with great potential include the generality of the Mashima reagent to deoxygenate nitrite, one example of which is demonstrated here. Another step worth exploration is its potential for deoxygenation of nitrosyl itself, as well as a determination of whether the resulting metal nitrides could be converted to silyl imines and even the bis-silyl amide ligand, $\mathrm{N}\left(\mathrm{SiMe}_{3}\right)_{2}$, these being one- and two-electron reductions of the metal, respectively. More broadly still, can the Mashima reagent deoxygenate other oxyanions: perchlorate, sulfite, phosphite, and even carbonate?

\section{Conflicts of interest}

There are no conflicts to declare.

\section{Acknowledgements}

We acknowledge funding from Indiana University Office of Vice President for Research and the National Science Foundation, Chemical Synthesis Program (SYN), by grant CHE-1362127, as well as the services of the Nanoscale Characterization Facility at IU. Diffraction data was collected at ChemMatCARS Sector 15, which is principally supported by the Divisions of Chemistry (CHE) and Materials Research (DMR), National Science Foundation, under grant number NSF/CHE-1346572. Use of the Advanced Photon Source, an Office of Science User Facility operated for the U.S. Department of Energy (DOE) Office of Science by Argonne National Laboratory, was supported by the U.S. DOE under Contract No. DE-AC02-06CH11357.

\section{Notes and references}

1 M. Duca and M. T. M. Koper, Energy Environ. Sci., 2012, 5, 9726.

2 N. Gruber and J. N. Galloway, Nature, 2008, 451, 293-296.

3 D. E. Over, S. C. Critchlow and J. M. Mayer, Inorg. Chem., 1992, 31, 4643-4648.

4 Z. P. Liu and P. Hu, Top. Catal., 2004, 28, 71-78.

5 R. H. Holm, Chem. Rev., 1987, 87, 1401-1449.

6 J. H. Enemark, J. J. Cooney, J. J. Wang and R. H. Holm, Chem. Rev., 2004, 104, 1175-1200.

7 S. Bontemps, Coord. Chem. Rev., 2016, 308, 117-130. 
8 H. D. Hausen, O. Mundt and W. Kaim, J. Organomet. Chem., 1985, 296, 321-337.

9 W. Kaim, Angew. Chem., 1981, 93, 621-622.

10 T. Saito, H. Nishiyama, H. Tanahashi, K. Kawakita, H. Tsurugi and K. Mashima, J. Am. Chem. Soc., 2014, 136, 5161-5170.

11 T. Saito, H. Nishiyama, K. Kawakita, M. Nechayev, B. Kriegel, H. Tsurugi, J. Arnold and K. Mashima, Inorg. Chem., 2015, 54, 6004-6009.

12 S. Rej, S. Pramanik, H. Tsurugi and K. Mashima, Chem. Commun., 2017, 53, 13157-13160.

13 V. Mougel, K. W. Chan, G. Siddiqi, K. Kawakita, H. Nagae, H. Tsurugi, K. Mashima, O. Safonova and C. Coperet, ACS Cent. Sci., 2016, 2, 569-576.

14 K. Yamamoto, K. W. Chan, V. Mougel, H. Nagae, H. Tsurugi, O. V. Safonova, K. Mashima and C. Coperet, Chem. Commun., 2018, 54, 3989-3992.

15 P. K. Majhi, H. Ikeda, T. Sasamori, H. Tsurugi, K. Mashima and N. Tokitoh, Organometallics, 2017, 36, 1224-1226.

16 T. Yurino, Y. Ueda, Y. Shimizu, S. Tanaka, H. Nishiyama, H. Tsurugi, K. Sato and K. Mashima, Angew. Chem., Int. Ed., 2015, 54, 14437-14441.

17 M. K. Assefa, G. Wu and T. W. Hayton, Chem. Sci., 2017, 8, 7873-7878.

18 S. Xu, D. C. Ashley, H.-Y. Kwon, G. R. Ware, C.-H. Chen, Y. Losovyj, X. Gao, E. Jakubikova and J. M. Smith, Chem. Sci., 2018, 9, 4950-4958.

19 C. L. Ford, Y. J. Park, E. M. Matson, Z. Gordon and A. R. Fout, Science, 2016, 354, 741-743.

20 Y. M. Kwon, M. Delgado, L. N. Zakharov, T. Seda and J. D. Gilbertson, Chem. Commun., 2016, 52, 11016-11019.

21 K. T. Burns, W. R. Marks, P. M. Cheung, T. Seda, L. N. Zakharov and J. D. Gilbertson, Inorg. Chem., 2018, 57, 9601-9610.

22 C. Uyeda and J. C. Peters, J. Am. Chem. Soc., 2013, 135, 1202312031.

23 J. H. Enemark, R. D. Feltham, B. T. Huie, P. L. Johnson and K. B. Swedo, J. Am. Chem. Soc., 1977, 99, 3285-3292.

24 R. D. Feltham and J. H. Enemark, Topics in Stereochemistry, John Wiley \& Sons, Inc., 1981.

25 J. R. Dethlefsen, A. Dossing and E. D. Hedegard, Inorg. Chem., 2010, 49, 8769-8778.
26 H.-Y. Cheng, S. Chang and W.-C. Liao, Comput. Theor. Chem., 2006, 776, 77-82.

27 A. Levina, P. Turner and P. A. Lay, Inorg. Chem., 2003, 42, 5392-5398.

28 I. Shim, K. A. Gingerich, K. Mandix and X. Feng, Inorg. Chim. Acta, 1995, 229, 455-460.

29 R. C. Maurya, S. K. Jaiswal, S. Mukherjee and I. B. Khan, Transition Met. Chem., 1992, 17, 530-532.

30 K.-B. Shiu, J. L. Chou, Y. Wang and G.-H. Lee, J. Chem. Soc., Dalton Trans., 1990, 0, 1989-1991.

31 W. R. Robinson, D. E. Wigley and R. A. Walton, Inorg. Chem., 1985, 24, 918-924.

32 D. E. Wigley and R. A. Walton, Inorg. Chem., 1983, 22, 31383143.

33 J. H. Enemark, M. S. Quinby, L. L. Reed, M. J. Steuck and K. K. Walthers, Inorg. Chem., 1970, 9, 2397-2403.

34 C. M. Lukehart and J. M. Troup, Inorg. Chim. Acta, 1977, 22, 81-86.

35 K. Wieghardt, K. Quilitzsch and J. Weiss, Inorg. Chim. Acta, 1984, 89, L43-L45.

36 R. G. Bhattacharyya and G. P. Bhattacharjee, Polyhedron, 1983, 2, 1221-1224.

37 T. L. Daulton and B. J. Little, Ultramicroscopy, 2006, 106, 561573.

38 J. W. Dethlefsen, A. Døssing and A. Kadziola, Inorg. Chim. Acta, 2009, 362, 1585-1590.

39 F. G. Herring, P. Legzdins, W. S. McNeil, M. J. Shaw, R. J. Batchelor and F. W. B. Einstein, J. Am. Chem. Soc., 1991, 113, 7049-7050.

40 L. M. Carruthers, C. L. Closken, K. L. Link, S. N. Mahapatro, M. Bikram, J. L. Du, S. S. Eaton and G. R. Eaton, Inorg. Chem., 1999, 38, 3529-3534.

41 F. Neese, J. Phys. Chem. Solids, 2004, 65, 781-785.

42 "Deoxygenation" here is distinct from (non-redox) conversion of $\mathrm{NO}_{2}{ }^{-}$to $\mathrm{NO}^{+}$with protons; $\mathrm{NO}^{+}$is simply the anhydride of protonated nitrous acid, $\mathrm{H}_{2} \mathrm{ONO}^{+}$.

43 A. Y. Kovalevsky, G. King, K. A. Bagley and P. Coppens, Chem.-Eur. J., 2005, 11, 7254-7264.

44 W. Kaim, A. Lichtblau and H.-D. Hausen, J. Organomet. Chem., 1993, 456, 167-173.

45 J. Baumgarten, C. Bessenbacher, W. Kaim and T. Stahl, J. Am. Chem. Soc., 1989, 111, 2126-2131.

46 W. Kaim, J. Chem. Soc., Perkin Trans. 2, 1985, 1633-1637. 